nomena as the disturbance of sex-ratios in declining populations, when, for example, if there are five males to every female it might cause little harm to take a male, but a disaster to take a female.

Finally, it seems time that much conservation legislation was revised to give better protection for potentially rare new forms while they are identified, perhaps by providing general protection for all harmless wildlife. In areas with restrictions on collecting anything at all, revision may also be needed to permit the preservation of natural casualties.

W. R. P. Bourne, 3 Contlaw Place, Milltimber, Aberdeen AB1 ODS, Scotland.

\section{Cows give badgers TB after all}

The badger-culling operations carried out in the UK in an attempt to eradicate bovine tuberculosis have failed to reduce the level of tuberculosis breakdowns in cattle herds in Britain since 1974 (Bovine Tuberculosis in Badgers. 15th Annual Report, Ministry of Agriculture, Fisheries and Food, October 1991). The reason is simple: badgers found to have TB after a herd breakdown contracted the disease from cattle, and not vice versa.

It has always been assumed that the 2 per cent of open-lesion infectious cattle are discovered by routine testing and removed before they have passed on TB to other cattle or badgers. But an average of 4.3 reactors/breakdown suggest some transmission between cattle as well as environmental contamination.

A largely forgotten French study a century ago showed that earthworms could carry viable bacilli, thus suggesting a very efficient transfer mechanism from cow to badger. Earthworms help to decompose cow pats, and earthworms make up 50 per cent of badger diet annually. Infection from this dietary route and head lymph nodes, rapidly becomes an apparent 'respiratory' case via the blood. Badger lungs often contain silica dust particles from living underground and the immunosuppressed lung tissue succumbs easily to TB. Even 6-month-old cubs may be acute TB cases.

Finding infected badgers some months after a bad herd breakdown is almost inevitable, given such an efficient transfer mechanism from cattle. Former blackspot counties in the Midlands have low levels in badgers and cattle, suggesting badger TB dies out when not topped up by recurring herd incidents. Culling badgers is hence totally unjustified on economic or scientific grounds.

M. Hancox on behalf of National Federation of Badger Groups, 72 Bisley Old Road, Stroud, Gloucestershire, GL5 1NB.

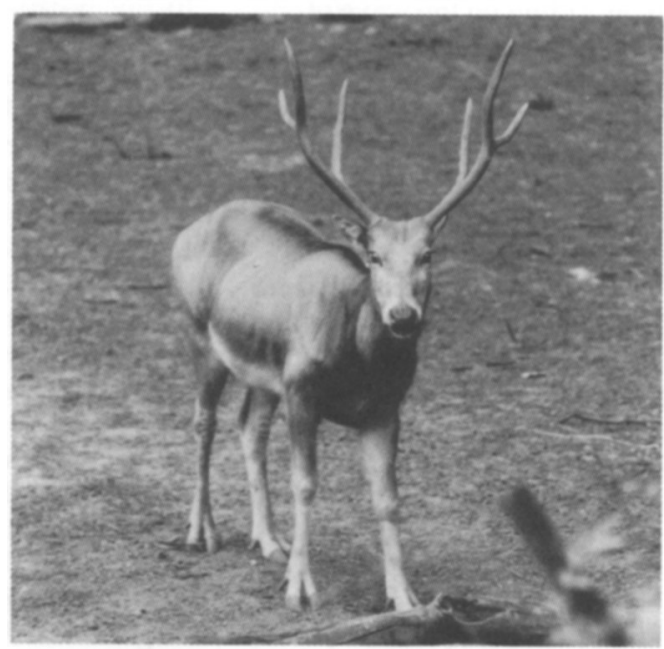

Père David's deer Elaphurus davidianus (WWF/F. Vollmar).

\section{Père David's deer}

During a recent visit to China I had a rare opportunity to see the flourishing herd of Père David's deer and so read the Briefly item on the deer reintroduction (Oryx , 26, 12) with interest. The deer live in Nan Haizi Milu Park, the former Imperial Deer Park situated some $60 \mathrm{~km}$ to the south of Beijing, and not in the grounds of the Imperial Palace. as your source states. As far as I know it was here that Père David noticed the deer in 1865 and managed to buy several from the official in charge. The first reintroduction, of 20 deer, in 1985, was augmented by a further 18 in 1986 . The park is run by the Beijing Milu Ecological Research Centre under Professor Wang Zongyi.

Richard Willan, Old Hill, Lurgashall, Petworth, Sussex GU28 9HB. 